\title{
Radyal sinir ile ilgili tuzak nöropatiler
}

\section{Compression neuropathies related to radial nerve}

\author{
Mustafa Özkan
}

Dokuz Eylül Üniversitesi Tıp Fakültesi, Ortopedi ve Travmatoloji Anabilim Dalı, İzmir

\begin{abstract}
Radyal sinir tuzaklanması radyal sinirin anatomik seyri boyunca değişik bölgelerde ve farklı nedenlere bağlı olarak oluşabilir. Sinirin tuzaklanma nedeniyle basıya uğraması ve hasarlanması, ekstansör veya supinatör kas grubunda fonksiyon bozukluğu ile radyal sinirin duyu dalının innerve ettiği bölgede uyuşukluk ya da parestezi ile sonuçlanır. Klinik semptomlar genelde, ağrı, kas güçsüzlüğü ve fonksiyon bozukluğudur.

Radyal sinir tuzaklanması en sık üç bölgede olmaktadır: dirsek üzeri, posterior interosseöz düzeyi, önkol distali ve el bileği. Bunlar içinde önemli bir sıklığa sahip, posterior interosseöz dalın tuzaklanması ise genelde önkol proksimal kesimde, supinatör kas liflerinin arasından geçtiği noktada olmaktadır. Posterior interosseöz sinirin tuzaklanmasına yol açan iki ayrı klinik tablo olan, posterior interosseöz sendrom ve radyal tünel sendromunun ayrımı önemlidir. Radyal tünel sendromu, temelde klinik bulgulara dayanan bir dışlama tanısıdır. Radyal sinir tuzaklanmalarında tedavi, mevcut patolojiye bağlı olarak, konservatif veya cerrahi olabilir.
\end{abstract}

Anahtar sözcükler: radyal sinir; anatomi; tuzaklanma; sendrom; tünel; tedavi
Radial nerve can be compressed at any site and by various etiologies during its anatomical course. Compression or injury to the nerve can cause denervation of the extensor or supinator muscles and numbness or paresthesia in the distribution area of the radial sensory nerve. Common clinical symptoms include pain, muscle weakness or dysfunction.

Entrapment of the radial nerve mostly occurs at 3 anatomical regions: proximal to the elbow, at the level of posterior interosseous nerve, distal forearm or wrist. Vast majority of the cases are presented with the entrapment of the posterior interosseous branch of radial nerve in the proximal forearm where the nerve passes through the fibers of supinator muscle. Differential diagnosis of two discrete conditions that are referred as posterior interosseous syndrome and radial tunnel syndrome is essential and rather based on clinical findings. Radial tunnel syndrome can be diagnosed based on clinical criteria those primarily include clinical symptoms; and it is, in principle, a diagnosis of exclusion. Treatment of radial nerve entrapment can be conservative or surgical depending on the etiology itself.

Key words: radial nerve; anatomy; entrapment; syndrome; tunnel; treatment

\section{ÖĞRENIM HEDEFLERi}

1. Radyal sinir anatomisi.

2. Radyal sinir klinik anatomi.

3. Radyal sinir tuzak nöropatileri ve kliniği.

4. Radyal Tünel sendromu tanı ve tedavisi.

\section{ANATOMI}

Radyal sinir, C5-T1 köklerinden köken alarak pleksus posterior korddan çıkar. Triseps, brakiyoradyalis, ekstansör karpi radyalis longus ve ankenous kaslarını direkt olarak, derin dalı vasıtasıyla ekstansör karpi

radyalis brevis ve supinatoru, derin dalın devamı olan posterior interosseöz sinir (PIN) ile ekstansör dijitorum, ekstansör dijiti minimi, ekstansör karpi ulnaris, abduktor pollisis longus, ekstansör pollisis brevis, ekstansör pollisis longus ve ekstansör indisis kaslarını innerve eder. Yüzeyel duyu dallarından posterior brakiyal kutanöz dalı kolun dorsal duyusunu, posterior antebrakiyal kutanöz dalı ise önkol dorsal kesiminin duyusunu taşır. ${ }^{[1]}$ Aksiller bölgeyi geçmeden önce veya hemen sonra, duyusal posterior brakiyal kutanöz dalı ve triseps kasının uzun ve mediyal başlarını innerve eden motor dallarını verir. ${ }^{[2]}$ Aksiller bölgeyi etkileyen travmalarda (örneğin; uzun süre koltuk değneği kullanımı

- Illetişim adresi: Prof. Dr. Mustafa Özkan, Dokuz Eylül Üniversitesi Tıp Fakültesi, Ortopedi ve Travmatoloji Anabilim Dalı, 35340 İzmir Tel: 0532 - 4117904 e-posta: ozkandiver@gmail.com

- Geliș tarihi: 13 Ekim 2015 Kabul tarihi: 13 Ekim 2015 
vb.), radyal sinirin innerve ettiği tüm kaslarda güçsüzlük ve ilgili alanlarda duyu kusuru oluşur. Daha sonra radyal sinir aksillayı terk etmek için triangüler boşluğu geçer. Triangüler boşluğun lateral sınıını humerus, mediyal sınırını triseps uzun başı ve teres majör liflerinin bir kısmı, alt sınırını ise teres majör üst lifleri oluşturmaktadır.

Humerus $1 / 3$ proksimal kesimde oluşan radyal sinir yaralanmalarında, triseps kasını innerve eden motor dallar daha önce çıktığından, triseps gücü normal bulunabilir, ancak bu lezyonlarda 'düşük el' tablosu görülür. Bu durumda, el bileği ve metakarpofalangeal eklemlerde ekstansiyon yapılamaz.

Humerus $1 / 3$ proksimal ve orta kesim arasında radyal sinir, triseps kasının uzun ve mediyal başları arasından geçerek humerus spiral oluğunda a. profunda brakii ile beraber ilerler. Daha sonra, inferolateralde yer alan intermusküler septum ile humerus lateral sınırına ulaşır. Spiral oluk $\mathrm{n}$. radyalisin sıklıkla hasarlanabildiği bir bölgedir.

Radyal sinirin kolda verdiği son dal, ekstansör karpi radyalis longus kasını innerve eder. Kesici ve delici travmalar, kronik bası (örneğin; Cumartesi gecesi paralizisi veya anestezi sırasında oluşan basılar) veya eski humerus kırığı sonrası kallus oluşumu gibi durumlar$\mathrm{da}$, hasar oluşabilir. Bu hastalarda, düşük el tablosuna rağmen triseps gücü korunmuştur.

Lateral intermusküler septumda ilerleyen sinir, lateral epikondilin yaklaşı $8-10 \mathrm{~cm}$ üzerinde lateral intermusküler septumu delerek, kolun fleksör kompartmanına girer. Burada, kolun distalinde, mediyalde brakiyalis, lateralde brakiyoradyalis kaslarının arasında ve brakiyoradyalis kasının mediyal sınırının hemen altında olacak şekilde seyreder ve lateral epikondil seviyesine ulaşır. Bu seyir, radyal tünel seyri olarak da adlandırılır. ${ }^{[3]}$

Radyal sinir, lateral musküler septumda, Frohse arkı adı verilen önkol proksimalinde bulunan supinator arkta, ekstansör karpi radyalis longus ve brakiyoradyalis kasları arasındaki yüzeyel seyri sırasında, bası ve travmaya maruz kalabilir. ${ }^{[4]}$

Lateral epikondilin önünden, antekübital fossanın anterolateralinde brakiyoradyalis kasının posteriorundan geçen radyal sinir, kübital fossa sonrası, brakiyoradyalis ve ekstansör karpi radyalis longus kasları arasında seyreder. Burada, ekstansör karpi radyalis brevise motor dal vererek, dirseğin $3 \mathrm{~cm}$ üstü veya altı olacak şekilde yüzeyel duyu ve derin motor dallarına (posterior interosseöz sinir) ayrilır. ${ }^{[5]}$

İzole duyusal sinir olan radyal sinirin yüzeyel dalı, brakiyoradyalis kası altında ve supinator kas anteriorunda seyreder. Bu bölgede sinir, radyal arterin lateralinde kalır. Dirsek bölgesinin yaklaşık $15 \mathrm{~cm}$ distalinde, brakiyoradyalis kası ile ekstansör karpi radyalis longus kasının tendonları arasında kalacak şekilde yüzeyelleşir ve önkol distaline doğru ilerler. Bu sinir, elin dorsal tarafı, 1. ve 2. parmak dorsal yüzü, 3. parmak radyal tarafta, proksimal interfalangeal ekleme kadar olan taraf ve enfiye çukurunun duyusunu alır. Enfiye çukuru, el dorsalinde 1. ve 2. parmak arasında, ekstansör pollisis longus ve abduktor pollisis longus tendonları tarafından sınırlanan, çukur şeklinde bir bölgedir. Radyal sinirin duyusal dalının tuzak nöropatisinin, nadir olmakla beraber, yaklaşık insidansı \%0,003'tür. ${ }^{[6]}$

Supinator kasın innervasyonu, nadiren değişiklik gösterir ve posterior interosseöz sinir, supinator kası genelde bu arkı geçmeden innerve eder. PiN, tam kesilerinde hasta başparmak ve diğer parmakların metakarpofalangeal eklem ekstansiyonunda zorluk çeker; düşük parmak deformitesi oluşur. Bu seviyede, ekstansör karpi radyalis brevis, ekstansör karpi radyalis longus, brakiyoradyalis ve supinator kaslar korunur. El bileği ekstansiyonu sırasında, radyal tarafa deviyasyon olur. ${ }^{[3]}$

Radyal tünel olarak tanımlanan bölge, sinirin lateral intermusküler septumu delip çıktığı ve bu bölgedeki kas, fasya ve fibröz bantların oluşturduğu bir bölgedir. Radyal tünel, anatomik olarak radius başından supinator kasın alt sınırına kadar uzanmaktadır ve sınırlarını, supinator, ekstansör karpi radyalis longus, ekstansör karpi radyalis brevis ve brakiyoradyalis kasları oluşturur. ${ }^{[7]} \mathrm{Bu}$ anatomik oluşum, radyal sinirin ana dalı ile her iki terminal dalın proksimal bölümlerini çevreler.

Saf motor sinir olan PiN, oblik seyrine devam ederek, ekstansör kompartmana ulaşır. Abduktor pollisis longus kasının üzerinde kalacak şekilde, ekstansör karpi ulnaris, ekstansör dijiti minimi ve ekstansör dijitorum kaslarının altında, aşağı doğru iner. Önkol distalinde ise, ekstansör pollisis brevis kasını delerek ya da üstünde seyrederek, radius ve ulna arasında interosseöz membrana ulaşır. PiN, posterior interosseöz arter ile beraber seyreder; ekstansör karpi ulnaris, ekstansör dijitorum abduktor pollisis longus, ekstansör pollisis longus ve brevis ile ekstansör dijiti minimi ve ekstansör indisis kaslarını innerve eder. ${ }^{[8]}$

\section{RADYAL SINIR TUZAK NÖROPATILERI}

Radyal sinir tuzaklanması, temelde üç kategoride incelenebilir: dirsek üzeri, posterior interosseöz sinir düzeyi, önkol distali ve bilekte yüzeyel duyusal dal.[9]

Dirsek üzerinde radyal sinir hasarı veya basısı, düşük el, brakiyoradyalis felci, ekstansör dijitorum felci ve radyal taraf el sırtında duyu kaybına yol açar. Burada, muayene sırasında dikkat edilmesi gereken bir nokta, parmak ekstansiyonu değerlendirilirken, hekimin el 
bileğini pasif ekstansiyonda tutmasıdır. Aksi halde, el bileği fleksiyonda kalacağından, parmakta oluşacak mekanik ekstansiyon yanıltıcı olabilir. Yüksek seviyeli radyal sinir yaralanmasının en sık nedeni, koltuk değneği kullanımıdır. Radyal sinirin dirsek üzerindeki basısısının bir diğer nedeni, "Cumartesi gecesi felci"dir. $\mathrm{Bu}$ sendrom, genelde kol yatağın kenarından sarkık olacak şekilde uyuya kalınması ile meydana gelen bası nedeniyle oluşur. Bu hastalarda, triseps kası sıklıkla korunmuştur. Sıklıkla, bu olgularda fonksiyon daha sonra tamamen geri kazanılır. Nadir görülse de, radyal sinirin, triseps kasının anormal insersiyosuna bağlı humerus orta kesimde, fibröz bantlar tarafindan basıya uğradığı görülen bazı olgular bildirilmiştir. ${ }^{[10]}$

Dirsek üstü seviyede radyal sinir tuzaklanması yaratan nedenlerden bir tanesi de, deplase humerus şaft kırıklarıdır. Kısmi veya tam paralizi şeklinde görülebilen hasarlanma, kırıkla aynı anda veya redüksiyonu takiben gelişebilir.

\section{POSTERIOR INTEROSSEÖZ SINIRIN (PIN) TUZAKLANMASI}

PiN'in basıya uğraması sonucu oluşan tuzak nöropatilerin yıllık insidansı yaklaşık \%0,03'tür. ${ }^{[11]}$

PiN'in en sık tuzaklandığı bölge, önkol proksimal kesimde, supinator kasların liflerinin arasından geçtiği noktadır. Burada, sıklıkla fibrotendinöz bant şeklinde görülen, Frohse arkı bulunur.

Sharrad, 1966 yılında ilk kez, fibröz bir bandın radyal siniri çaprazladığını ve serbestlenme sonrası fonksiyonların geri kazanıldığını ifade eden bir makale yayımlamıştır. Yirmi beş erişkin ve 10 adet fetüsun üst ekstremitelerini anatomik olarak inceleyen Spinner ve arkadaşları, PiN'in travmatik veya non-travmatik ilerleyici paralizisinde, Frohse pasajının anatomik bir rol oynayabileceğini düşünmüştür. Illk kez 1908'de Frohse tarafından tanımlanan bu arkın, yenidoğanların hiçbirinde sert tendinöz bir yapıda olmayıp, musküler yapıda olduğu görülmüştür. Bu yüzden, yarı dairesel fibröz arkın, önkolun tekrarlayan dönme hareketleri ile oluşabileceği düşünülmektedir. Tendinöz yapıda olan supinator kasın yüzeyel başının en proksimal bölümü, fibröz arkın oluşumunu sağlamaktadır. Bu yapı, lateral epikondilin uç kısmından başlar ve yarı dairesel şekilde, $1 \mathrm{~cm}$ aşağıda lateral epikondilin iç yüzeyine yapışır. PIN ise bu fibröz arkın altında seyreder. ${ }^{[12]}$

\section{RADYAL TÜNEL SENDROMU}

PiN tuzaklanması, temelde iki ayrı klinik tablo şeklinde olabilir. IIlki, 1972 yılında Roles ve Maudsley'in, PiN basısı ve ağrı arasında bir ilişki bularak, bu durumu "dirençli tenisçi dirseği ile beraber olan sinir tuzaklanması" şeklinde tanımladıkları tablodur. ${ }^{[13,14]}$ "Radyal tünel sendromu" (RTS) ifadesi ise, daha sonra 1993 yılında Eversmann tarafindan, sinirin supinator brevis kası altında tuzaklandığı durum için kullanılmış olsa da, aynı ifade daha sonra yayımlanan makaleler tarafindan radyal sinirin radyal tünelde (dirsekte) basıya uğrayarak fizyolojik semptomlara yol açtığı diğer durumlara da uyarlanarak kullanılmıştır. ${ }^{[15]}$

RTS'nin cinsiyete göre (K:E) görülme oranı 1:1-1:6 arasında değişmektedir ve hastalar, genellikle 30-50 yaş arasındadır. Bilateral tutulum nadirdir ve genellikle dominant taraf tutulur. RTS tanısı alan hastalarda, sıklıkla omuz instabilitesi, karpal tünel sendromu, tetik parmak veya diğer nedenlerle daha önce geçirilmiş bir cerrahi öyküsü bulunmaktadır. ${ }^{[16]}$

Radyal sinir ve derin dalı, tünel içerisinde beş ayrı noktada basıya uğrayabilir: lateral dirsek ekleminde radius başı çevresinde (radyokapitellar eklem anteriorunda osteoartrit veya fibröz bantlar), radyal rekürren damarlar civarı (Henry tasması), ekstansör karpi radyalis brevisin fibröz kenarı, radyal tünelin distal kenarı ve en sık görülen, Frohse arkı düzeyi (supinator kasın proksimal kısmı).

RTS'de altta yatan nedenin, sinirin radyal tünel seyri sırasında kesintili olarak basıya maruz kalması olduğu düşünülmektedir. ${ }^{[17]}$ Önkol zorlamalı pronasyonunun da, PiN'i Frohse arkı çevresinde basıya uğrattığını bildiren yayınlar mevcuttur. Bunlardan bir tanesi, Links ve arkadaşlarının yayımladığı makaledir. Bu makalede yazarlar, çift insizyon tekniği kullanılarak yapılan distal biseps onarımı sırasında, zorlamalı pronasyon nedeniyle PiN palsisi görülebildiği ve yine kadavra üzerinde yapmış oldukları çalışmada, pronasyon ile aynı bölgede PiN üzerinde basınç artışı tespit ettikleri bildirmişlerdir. ${ }^{[18]}$ Ayrıca, bir diğer çalışmada, Frohse arkı tendinöz olan hastalarda PiN üstüne binen basınç, pasif supinasyonda $46 \mathrm{mmHg}$ ile aktif supinasyonda $190 \mathrm{mmHg}$ arasında ölçülmüş ve bu seviyelerin kompresyon nöropatisi yapacak düzeyde olduğu belirtilmiştir. ${ }^{[19]}$

Rekürren radyal arter varyasyonlarının da radyal tünel sendromunun olası nedeni olabileceği, kadavra çalışmasında gösterilmiştir. ${ }^{[20]}$

RTS'nin değerlendirilmesinde, önkoldaki ağrının yerinin tespiti çok önemlidir. RTS'nin en önemli klinik belirtisi, radyal sinir üzerinde ve dirsek lateral epikondilin $5 \mathrm{~cm}$ distalinde oluşan hassasiyettir. Gece ağrısı sıktır ve zorlu supinasyon, dirsek ekstansiyonu veya el bileği fleksiyonu gibi sinire traksiyon yapan hareketlerde ağıı artar. Tanı koymak için, kabul edilmiş iki klinik 
test mevcuttur. Bunlardan bir tanesi, dirence karşı zorlu supinasyon, öteki ise el bileğinin zorlu hiperekstansiyonu ile önkol proksimali radyal tarafta radyal tünel üzerinde ağıı oluşmasıdır. Ayırıcı tanıda, hastanın el bileği ve dirseği ekstansiyonda iken orta parmak dirençli ekstansiyonunda ağrı oluşması ile tanımlanan "orta parmak" testinin patognomonik bir bulgu olduğunu belirten yazarlar olsa da, ağrının bu test ile çok nadir oluştuğunu bildiren çalışmalar da mevcuttur. ${ }^{[16,21]}$ RTS tanısında kullanılan diğer bir yararlı test ise, Loh ve arkadaşları tarafından tanımlanan ve önkol proksimalini volar yüzde, dirsek katlantısı distalinde dokuz ayrı noktaya ayıran testtir. Bu noktalar, $3 \times 3$ olacak şekilde, bir bozuk paranın yarı büyüklüğündedir. Lateral taraftaki sütunda bulunan iki proksimal noktada ağrı olması, RTS açısından anlamlıdır. ${ }^{[22]}$

Manyetik rezonans (MR) görüntüleme ve diğer görüntüleme yöntemlerinde patolojik bulgu yoktur. Ancak, bazı hastalarda, MR'de kas ödemi ve atrofisi görüldügünü belirten çalışmalar olsa da, bu konu halen tartışmalıdır. ${ }^{[23]}$

Tanı, RTS'ye özgü önkol bölümünde, özellikle gece artan ağrı ve yorgunluk olması ile konulur. Ancak, bu semptomlar sadece RTS'ye özgü olmadığından; ayırıcı tanıda, brakiyal pleksus inflamasyonu veya hasarı, biseps kasının tendinopatileri, lateral epikondilit, radyokapitellar eklem osteoartriti ve posterior plika sıkışması gibi, aynı bölgede ağrıya yol açabilen patolojiler ekarte edilmelidir. RTS, temelde klinik bulgulara dayanan bir dışlama tanısıdır. Özellikle, dirençli epikondilit olgularının RTS yönünden incelenmesi önemlidir. RTS'den, lateral epikondil üzerinde lokalize hassasiyetle ayrilan lateral epikondilitin, RTS ile beraber görülebildiği ve bu oranın $\% 21-41$ arası değiştiği gösterilmiştir. ${ }^{[24,25]}$ Öte yandan, RTS tanısı konulan hastaların \%5'inde lateral epikondilit de olduğu bildirilmiştir. ${ }^{[26]}$ RTS ayırıcı tanısında yer alan önemli başka bir hastalık, PiN'in radyal tünel sonrası basıya uğraması ile oluşan, PiN sendromudur. Başparmak ve diğer parmaklarda ekstansiyon güçsüzlüğü şeklinde görülen motor semptomlar, RTS ile ayrımını sağlar. PiN'in tam felcinin geliştiği durumda bile, ekstansör karpi radyalis fonksiyonu ve el bileği radyal deviyasyon ile ekstansiyon hareketleri korunur. ${ }^{[6]}$

Diğer yandan, ekstansör kas grubunda güçsüzlük olmaması ve tanının sadece klinik olarak konulabilmesi, radyal tünel sendromunun varlığı hakkında tartışmalara yol açmaktadır. ${ }^{[16]}$ Bu sendromun varlığını destekleyen yazarlar tarafindan, radyal sinire bası yaparak radyal tünel sendromuna (RTS) yol açan; kalınlaşan fasyal bantlar, radyal arterin tekrarlayıcı dalları, supinator kasın köşesi ve nadir olsa da hemanjiyom, lipom, radius başı dislokasyonu, inflame sinoviyum ya da aksesuvar kaslar gibi çeşitli nedenler gösterilmiştir. ${ }^{[14]} \mathrm{Bu}$ tanıyı desteklemeyen yazarların savunduğu bir nokta ise; RTS, PiN'in bası altında kalması sonucu oluşan bir tuzak nöropatisi olarak açıklanmış olmasına rağmen, elektromiyografi (EMG) veya sinir ileti çalışmalarında, bu hastalıkta hiçbir zaman bulgu olmamasıdır. Fakat, bu soruya da, motor sinirlerin ağrıyı da iletebildiği ve demiyelinize veya küçük miyelinli sinir liflerinin EMG ile değerlendirilemeyeceği şeklinde yanıt verilmektedir. ${ }^{[17]}$

RTS tedavisinde, konservatif ve cerrahi yöntemler kullanılabilir. Sık kullanılan konservatif yöntemler; el bileği splinti ile immobilizasyon, ultrasonografi uygulaması, fizik tedavi ve non-steroid anti-inflamatuvar (NSAi) ilaç kullanımıdır. Ayrıca, radyal tünel içerisine lokal anestezi vererek tam veya kısmi radyal sinir bloğu yapmak, diğer bir yöntemdir. Bunun dışında hastaya, günlük yaşam aktivitesi sırasında, uzamış dirsek ekstansiyonu, önkol pronasyonu ve el bileği fleksiyonundan kaçınması da önerilebilir. Ancak, konservatif tedavilerin başarısı halen tartışmalıdır ve üç ay içinde semptomlarda düzelme görülmediği takdirde cerrahi önerilmektedir. ${ }^{[6]}$

$\mathrm{Bu}$ olgularda, posterior interosseöz sinir cerrahi olarak ortaya konulduğunda, sinirin, genellikle radius başından gelen fibröz bantlar veya ekstansör karpi radyalis brevis kasının keskin tendinöz kenarı tarafından, Frohse arkı seviyesinde basıya uğradığı görülür. Çoğu hastada, cerrahi dekompresyonun sonuçları iyidir. Yaklaşım hangisi olursa olsun, sinirin Frohse arkı seviyesinde serbestlenmesi ve rekürren radyal damarların bağlanması çok önemlidir. ${ }^{[27]}$ Radyal sinirin cerrahi olarak serbestlenmesinde, temel olarak, PiN'e dorsal (Şekil 1) veya volar (Şekil 2) yaklaşımla ulaşılabilir. Bugün en sık kullanılan yaklaşımlar, anterior ve transbrakiyoradyal yaklaşımlardır. Bunun dışında ise, sinire dorsalden, brakiyoradyalis kası ve el bileği ekstansörleri arasından veya yine dorsalden, brakiyoradyalis ile ekstansör karpi radyalis longus, brevis kasları (mobile wad) ve parmak ekstansörleri arasından ulaşılan (Thompson) başka yaklaşımlar da mevcuttur. Anterior yaklaşımda, önkol supinasyonda iken, lateral epikondilden başlayan ve brakiyoradyalis ile biseps kasları arasındaki oluğa uzanan eğimli bir insizyon yapılır. Daha sonra, radyal sinir bulunarak, yüzeyel ve derin dallarını verdiği bifurkasyon seviyesine kadar takip edilerek, Frohse arkı seviyesinde serbestleştirilir. Anterior yaklaşım, eğer radyal sinirin dirsek proksimalinde de kompresyon şüphesi varsa, daha yararlıdır. Transbrakiyoradyal yaklaşımda ise, Thompson tarafindan tanımlanmış ve önkol pronasyonda iken el bileği ortasına doğru yapılanın daha anteriorundan bir insizyon yapılır. Brakiyoradyalis fasyası longitudinal olarak geçilerek, kas lifleri ayrılır ve radyal sinire ulaşılır. ${ }^{[17]}$ 

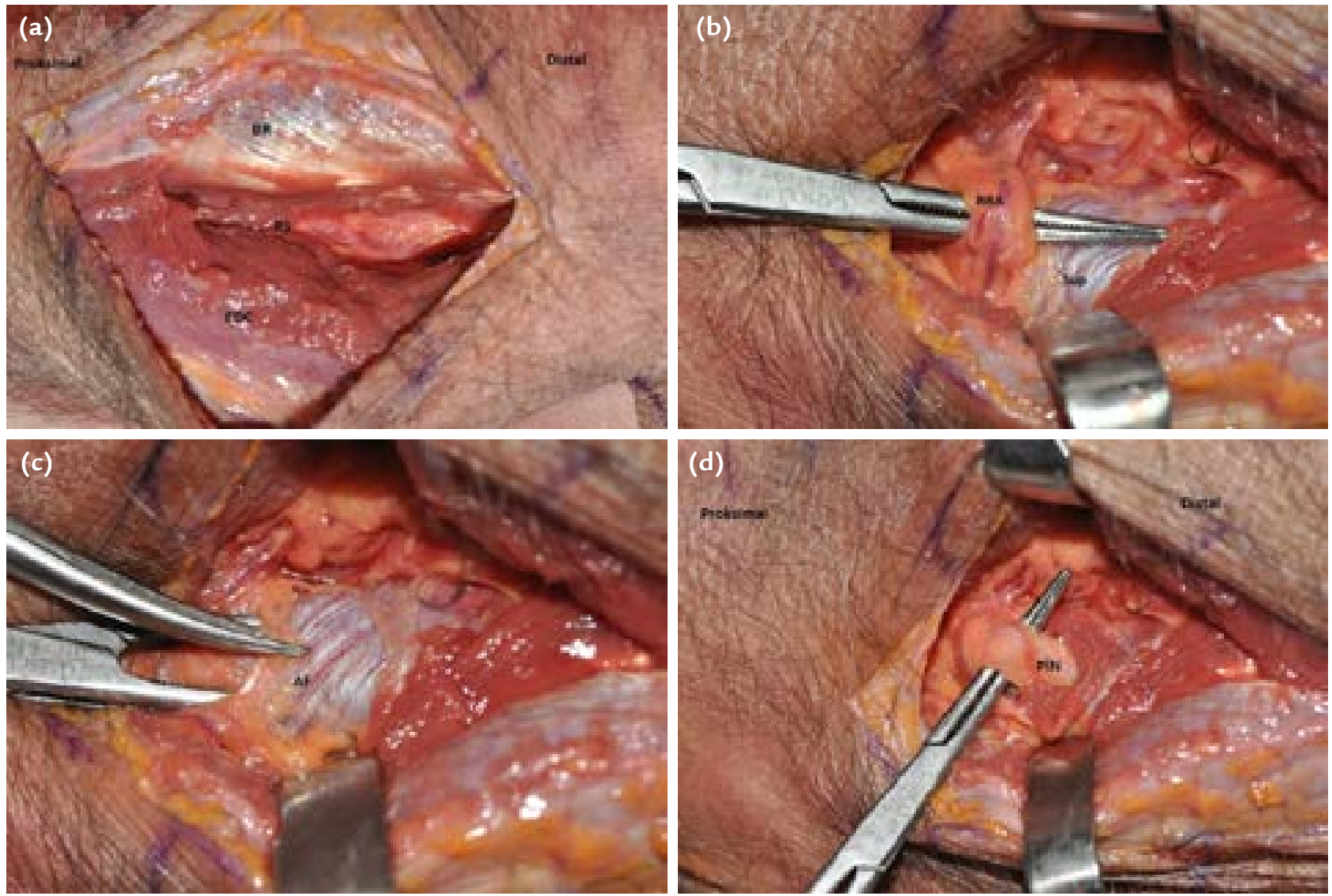

Şekil 1. a-d. Dorsal yaklaşım (BR, brakiyoradyalis kası; RS, radyal sinir; EDC, ekstansör dijitorum kommunis; RRA, rekürren radyal arter; Sup, supinator kas; AF, Frohse arkı; PiN, posterior interosseöz sinir).
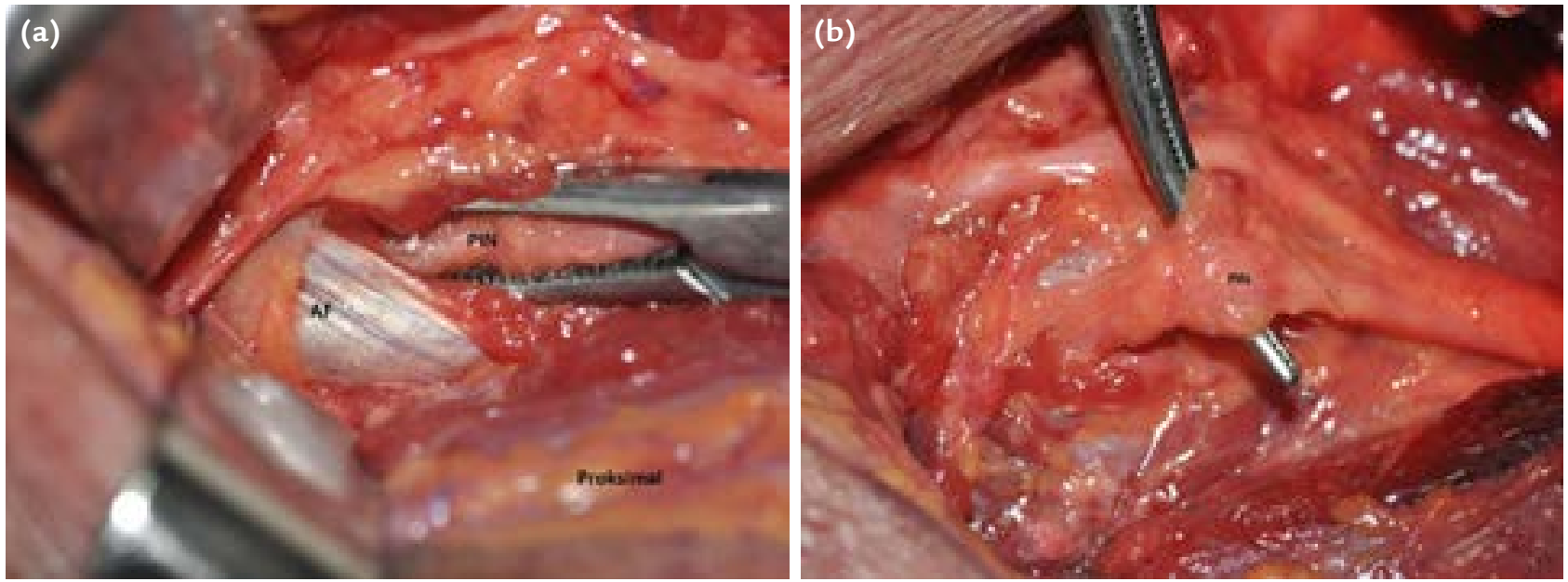

Şekil 2. a, b. Volar Yaklaşım (AF, Frohse arkı; PiN, posterior interosseöz sinir).

RTS'de cerrahi tedavi genelde başarılıdır. PIN'in tek başına serbestlendiği olgu serilerinde başarı oranları \%39-95 arası iken, beraberinde radyal sinir yüzeyel dalının serbestlendiği olgularda başarı oranı \%67-92 arasında bildirilmektedir. ${ }^{[28]}$ Stanley ve arkadaşlarına göre, dokuz ay içinde semptomların gerilememesi, başarısızlık olarak değerlendirilmelidir. ${ }^{[29]}$ Perez ve arkadaşları ise, yayımladıkları 42 hastalık olgu serisinde, radyal tünel sendromu nedeniyle posterolateral yaklaşım ile opere ettikleri hastalarda oldukça iyi sonuç elde 

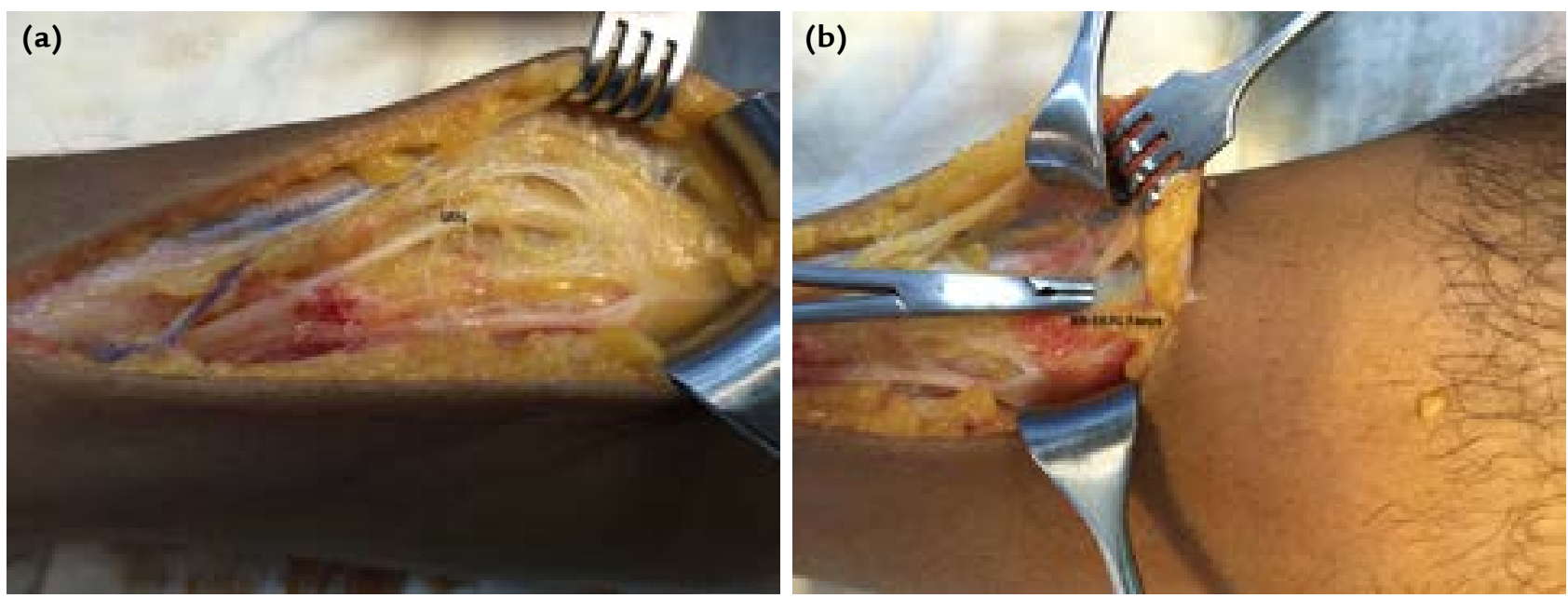

Şekil 3. a, b. Yüzeyel radyal sinir serbestlenmesi (SRN, yüzeyel radyal sinir) (a). Yüzeyel radyal sinirin brakiyoradyalis ile ekstansör karpi radyalis kasları arasında en fazla basıya uğradığı nokta (BR, brakiyoradyalis kası; EKRL, Ekstansör karpi radyalis longus kası) (b).

ettiklerini ve bu cerrahi tedavinin başarısının yüksek olduğunu bildirmişlerdir. ${ }^{[30]}$

PiN tuzaklanmasındaki ikinci klinik tabloda, el-bilek ve parmak ekstansiyonunda kademeli veya ani güç kaybı görülür. Temelde, radyal sinirin tünel içerisinde tuzaklanması RTS olarak isimlendirilirken, tünel sonrası PiN basısı posterior interosseöz sendromu olarak adlandırılır. Başlangıçta ağrı olsa da, bu öne çıkan bir bulgu değildir. Duyu kaybı yoktur. El-bilek ekstansiyonunda tam kayıp olmamakla birlikte, bilek radyale deviye olur. Genellikle, brakiyoradyalis, ekstansör karpi radyalis longus ve brevis ile supinator kas daha proksimaldeki dallardan innerve olduklarından, korunmuştur. EMG ile lezyonun yerinin saptanması mümkündür. Bası yapan bir kitle (lipom, gangliyon) veya Frohse arkı seviyesinde tuzaklanma, bu tabloya yol açabilmektedir. PiN'in cerrahi olarak gevşetilmesi, biseps ve brakiyoradyalis kasları arasında dirsek üzerinde başlayan ve önkol üst iç yüzünün ortasına kadar uzanan cilt insiyonu ile yapılır. Özellikle, radyal sinirin dallarının ortaya konulması ve PiN'in gevşetilmesi sırasında dikkatli olunmalıdır. Bazı olgularda, posterior interosseöz sinirin küçük distal dallarının tam dekompresyonu için, önkolda supinator kasa uzanan ek bir insizyon yapılabilir.

\section{WARTENBERG SENDROMU}

ilk kez 1932 yılında, Wartenberg tarafindan, beş hastada tanımlanmıştır. ${ }^{[31]}$ Radyal sinirin yüzeyel dalının geçici kompresyonu nedeniyle, el dorsali radyal tarafta anestezi, hipoestezi veya hiperestezi görülür.
İstirahat halinde de ağrı mevcuttur. Genellikle saat kayışları veya atletik bantlar nedeniyle oluşur. Sıklıkla radyal duysal sinir tuzaklanması "de Quervain" tenosinoviti ile beraberdir. Neden ortadan kalktıktan sonra, tamamen iyileşir. Ancak, künt travma ile görülen bu yüzeyel dalın ağrılı parestezisi, tedaviye daha dirençlidir. De Quervain tenosinoviti ve 1. parmak karpo-metakarpal eklem osteoartrozu ile ayırıcı tanısının yapılması lazımdır. Önemli bir diğer bulgu ise, Wartenberg sendromunda istirahatte de ağrı olması, de Quervain tensinovitinde ise ağrının istirahatte azalmasıdır.

İlk önce konsevatif tedavi denenmelidir. Dinlendirme, splintleme, bası yapacak saat kayışı, bilezik gibi takıların çıkartılması, anti-inflamatuvar ilaç kullanımı ile genellikle iyileşme sağlanır. Lokal steroid uygulaması yapılabilir.

Konservatif tedaviye cevap vermeyen olgularda, cerrahi tedavi ile dekompresyon yapılabilir. Radyal sinirin yüzeyel dalının brakiyoradyalis ile ekstansör karpi radyalis longus tendonları arasından girdiği bölge gevşetilmelidir (Şekil 3).

\section{KAYNAKLAR}

1. Maniker $\mathrm{AH}$. Radial and posterior interosseous nerve. In: Maniker $\mathrm{AH}$, editor. Operative exposures in peripheral nerve surgery. New York: Thieme Medical Publishers; 2005. p.48-61.

2. Lee CC, Tindal SC, Kliot M. Entrapment syndromes of peripheral nerve injuries. In: Winn HR, editor. Youmans Neurological Surgery, Vol 4, 5th ed. Philadelphia: Saunders; 2004. p.3921-39. 
3. Rengachary SS. Entrapment neuropathies. In: Wilkins $\mathrm{RH}$, Rengachary SS, editors. Neurosurgery, Vol IIIA, 2nd ed. New York, NY: McGraw-Hill; 1996. p.3073-98.

4. Chusid JG. The brachial plexus. In: Chusid JG, editor. Correlative Neroanatomy and Functional Neurology, 19th ed. Los Altos, California: Lange Medical Publication; 1985. p.140-50.

5. McGillicuddy JE, Sullivan SE. Entrapment/Compression Neuropathies. In: Batjer HH, Loftus CM, editors. Textbook of Neurological Surgery: Principles and Practice, Vol 3, 1st ed. Philadelphia: Lippincott Williams and Wilkins; 2003. p.2201-28.

6. Dang $\mathrm{AC}$, Rodner $\mathrm{CM}$. Unusual compression neuropathies of the forearm, part I: radial nerve. J Hand Surg Am 2009;34(10):1906-14. CrossRef

7. Portilla Molina AE, Bour C, Oberlin C, Nzeusseu A, Vanwijck $R$. The posterior interosseous nerve and the radial tunnel syndrome: an anatomical study. Int Orthop 1998;22(2):102-6.

8. Branch CL, Kelly DL, Lynch GC. Surgical Exposure of Peripheral nerves. In: Wilkins RH, Rengachary SS, editors. Neurosurgery, Vol IIIA, 2nd ed. New York, NY: McGraw-Hill; 1996. p.3147-67.

9. Aşır A, Topuz AK. Üst ekstremite Tuzak Nöropatilerinde Ayırıcı Tanı. İçinde: Zileli M, Demircan N, editörler. Periferik Sinir Cerrahisi, Vol 1, 1st ed. Türk Nöroşirürji Derneği Spinal ve Periferik Sinir Cerrahisi Grubu Yayınları No:6; 2008. p.259-73.

10. Manske PR. Compression of the radial nerve by the triceps muscle: a case report.J Bone Joint Surg Am 1977;59(6):835-6.

11. Van den Ende KI, Steinmann SP. Radial tunnel syndrome. J Hand Surg Am 2010;35(6):1004-6. CrossRef

12. Ozturk A, Kutlu C, Taskara N, Kale AC, Bayraktar B, Cecen A. Anatomic and morphometric study of the arcade of Frohse in cadavers. Surg Radiol Anat 2005;27(3):171-5.

13. Roles NC, Maudsley RH. Radial tunnel syndrome: resistant tennis elbow as a nerve entrapment. J Bone Joint Surg $\mathrm{Br}$ 1972;54(3):499-508.

14. Lister GD, Belsole RB, Kleinert HE. The radial tunnel syndrome. J Hand Surg Am 1979;4(1):52-9.

15. Sarhadi NS, Korday SN, Bainbridge LC. Radial tunnel syndrome: diagnosis and management. J Hand Surg $\mathrm{Br}$ 1998;23(5):617-9.

16. Bolster MA, Bakker XR. Radial tunnel syndrome: emphasis on the superficial branch of the radial nerve. J Hand Surg Eur Vol 2009;34(3):343-7. CrossRef

17. Moradi A, Ebrahimzadeh MH, Jupiter JB. Radial Tunnel Syndrome, Diagnostic and Treatment Dilemma. Arch Bone Jt Surg 2015;3(3):156-62.
18. Links AC, Graunke KS, Wahl C, Green JR, Matsen FA. Pronation can increase the pressure on the posterior interosseous nerve under the arcade of Frohse: a possible mechanism of palsy after two-incision repair for distal biceps rupture -clinical experience and a cadaveric investigation. J Shoulder Elbow Surg 2009;18(1):64-8. CrossRef

19. Werner CO, Haeffner F, Rosén I. Direct recording of local pressure in the radial tunnel during passive stretch and active contraction of the supinator muscle. Arch Orthop Trauma Surg 1980;96(4):299-301.

20. Ozkan M, Bacakoğlu AK, Gül O, Ekin A, Mağden O. Anatomic study of posterior interosseous nerve in the arcade of Frohse. J Shoulder Elbow Surg 1999;8(6):617-20.

21. Hagert CG, Lundborg G, Hansen T. Entrapment of the posterior interosseous nerve. Scand J Plast Reconstr Surg 1977;11(3):205-12.

22. Loh YC, Lam WL, Stanley JK, Soames RW. A new clinical test for radial tunnel syndrome -the Rule-of-Nine test: a cadaveric study. J Orthop Surg (Hong Kong) 2004;12(1):83-6.

23. Ferdinand BD, Rosenberg ZS, Schweitzer ME, Stuchin SA, Jazrawi LM, Lenzo SR, Meislin RJ, Kiprovski K. MR imaging features of radial tunnel syndrome: initial experience. Radiology 2006;240(1):161-8.

24. Ritts GD, Wood MB, Linscheid RL. Radial tunnel syndrome. A ten-year surgical experience. Clin Orthop Relat Res 1987;(219):201-5.

25. Jebson PJ, Engber WD. Radial tunnel syndrome: longterm results of surgical decompression. J Hand Surg Am 1997;22(5):889-96.

26. Lee JT, Azari K, Jones NF. Long term results of radial tunnel release -the effect of co-existing tenn is elbow, multiple compression syndromes and workers' compensation. J Plast Reconstr Aesthet Surg 2008;61(9):1095-9.

27. Clavert P, Lutz JC, Adam P, Wolfram-Gabel R, Liverneaux P, Kahn JL. Frohse's arcade is not the exclusive compression site of the radial nerve in its tunnel. Orthop Traumatol Surg Res 2009;95(2):114-8. CrossRef

28. Lawrence $T$, Mobbs P, Fortems $Y$, Stanley JK. Radial tunnel syndrome. A retrospective review of 30 decompressions of the radial nerve. J Hand Surg Br 1995;20(4):454-9.

29. Stanley J. Radial tunnel syndrome: a surgeon's perspective. J Hand Ther 2006;19(2):180-4.

30. Simon Perez C, García Medrano B, Rodriguez Mateos JI, Coco Martin B, Faour Martin O, Martin Ferrero MA. Radial tunnel syndrome: results of surgical decompression by a postero-lateral approach. Int Orthop 2014;38(10):2129-35. CrossRef

31. Wartenberg R. Cheiralgia paresthetica (isolierte Neuritis des Ramus Superficialis Nervi Radialis). Z Ges Neurol Psychiatr 1932;141:145-55. 